\title{
Wind Farm Stabilization by using DFIG with Current Controlled Voltage Source Converters Taking Grid Codes into Consideration
}

\author{
Kenneth Eloghene Okedu* Non-member \\ S.M. Muyeen ${ }^{* *} \quad$ Non-member \\ Rion Takahashi* ${ }^{*}$ Member \\ Junji Tamura* Member
}

\begin{abstract}
Recent wind farm grid codes require wind generators to ride through voltage sags, which means that normal power production should be re-initiated once the nominal grid voltage is recovered. However, fixed speed wind turbine generator system using induction generator (IG) has the stability problem similar to the step-out phenomenon of a synchronous generator. On the other hand, doubly fed induction generator (DFIG) can control its real and reactive powers independently while being operated in variable speed mode. This paper proposes a new control strategy using DFIGs for stabilizing a wind farm composed of DFIGs and IGs, without incorporating additional FACTS devices. A new current controlled voltage source converter (CC-VSC) scheme is proposed to control the converters of DFIG and the performance is verified by comparing the results with those of voltage controlled voltage source converter (VC-VSC) scheme. Another salient feature of this study is to reduce the number of proportionate integral (PI) controllers used in the rotor side converter without degrading dynamic and transient performances. Moreover, DC-link protection scheme during grid fault can be omitted in the proposed scheme which reduces overall cost of the system. Extensive simulation analyses by using PSCAD/EMTDC are carried out to clarify the effectiveness of the proposed CC-VSC based control scheme of DFIGs.
\end{abstract}

Keywords : Voltage source converter, Doubly fed induction generator (DFIG), Grid fault, Grid codes, Wind energy, Stability.

\section{Introduction}

The response of wind generators to grid disturbances is an important issue nowadays, because the installations of wind generators are steadily increasing. Therefore, it is important for utilities or grid companies to study the effects of various voltage sags on the corresponding wind turbine responses [1-3]. The emerging grid codes demand that wind farms should have a good performance with respect to voltage control capability and robust behavior against frequency and voltage variations under fault condition. The induction generator (IG) is used, in general, as fixed speed wind turbine (FSWT) generator due to its superior characteristics such as brushless and rugged construction, low cost, maintenance free, and operational simplicity. However, it requires large reactive power to recover the air gap flux when a short circuit fault occurs in power system. Thus reactive power compensation from power network or other devices is needed for the FSWT wind farm. The installation of compensation units, like static synchronous compensator (STATCOM) [4], superconducting magnetic energy storage (SMES) [5], and energy capacitor system (ECS) [6], in a wind farm composed of fixed speed wind turbines (FSWTs) to overcome voltage sag during a grid fault, increases the system overall cost. The amount of necessary dynamic reactive power compensation depends generally on the type of wind turbine generator system (WTGS)

\footnotetext{
* Department of Electrical and Electronic Engineering, Kitami Institute of Technology, Hokkaido, Japan, corresponding author: Kenneth E. Okedu, e-mail: (kenokedu@yahoo.com or dse09801@std.kitami-it.ac.jp)

** Department of Electrical Engineering, The Petroleum Institute, Abu Dhabi, U.A.E.
}

and is influenced by relevant electrical and mechanical parameters of that system.

The doubly fed induction generator (DFIG) has very attractive characteristic as a wind generator because the power processed by the power converter is only a fraction of the total power rating of the DFIG. This is typically $20-30 \%$, and therefore its size, cost, and losses are much smaller compared to a full size power converter used in other types of variable speed wind generators [7]. DFIG can operate at a wide range of speed depending on the wind speed or other specific operation requirements. Thus, it allows a better capture of wind energy [8-10]. The dynamic slip control and pitch control are the other salient features which help to augment the system stability. In addition, DFIG has better behavior concerning system stability during short-circuit faults in comparison with IG, because of its capability of independent control of active and reactive power output [11]. The superior dynamic performance of the DFIG results from the frequency converter which typically operates with sampling and switching frequencies of above $2 \mathrm{kHz}$ [12]. Therefore, it is paramount to use a variable speed wind turbine (VSWT) system like a DFIG to stabilize a FSWT (IG) in a wind farm, because the DFIG system can also control reactive power in a similar manner to a STATCOM, SMES, or ECS, and thus the reactive power compensation can be implemented at a lower cost.

This paper presents a new coordinated control scheme where IGs are stabilized by using DFIGs excited by current controlled voltage source converter (CC-VSC). Though the research about CC-VSC has already been reported in many literature, the application and control strategy of CC-VSC that suits well for DFIG to stabilize wind farm has so far not been reported yet. The 
proposed CC-VSC based DFIG can operate well with minimum number of PI controllers in rotor side converter and without the support of DC-link protection scheme. Thus, the intricacy of the controller design can be reduced considerably. Moreover the two-mass drive train model is considered for all wind generators, as it has great influence on the transient characteristics [13]. Simulations were carried out using PSCAD/EMTDC [14] for a three line to ground fault (severe case) in the power system, to show the effectiveness of the proposed control scheme to stabilize the entire wind farm. The transient stability index of the system is also analyzed for symmetrical and unsymmetrical fault conditions and also for different fault locations in the power system to show the overall stabilizing effect of CC-VSC based DFIG system. Obtained results are compared with those obtained using voltage controlled voltage source converter (VC-VSC) based DFIG scheme reported in [15]. Dynamic analysis using real wind speed data is also presented to show the performance of the proposed system under practical situations.

\section{Model System}

A model system shown in Fig.1 [15] is used in this study, where two wind farms are connected to the main power system. Aggregated wind farm model is considered in this analysis for fast computing. Each wind farm is composed of 1 DFIG and 3 IGs. The wind turbine modeling, parameters of the generators, ratings of the DFIGs excitation circuit including DC-link protection scheme and the basic control of the DFIGs using VC-VSC strategy have been presented in [15].

The IEEE generic turbine model and approximate mechanical-hydraulic speed governing system [16] is used for synchronous generator 1 (SG1). The IEEE "non-elastic water column without surge tank" turbine model and "PID control including pilot and servo dynamics" speed-governing system [17] is used for synchronous generator 2 (SG2). IEEE alternator supplied rectifier excitation system (ACIA) [18] is used in the exciter model of both synchronous generators.

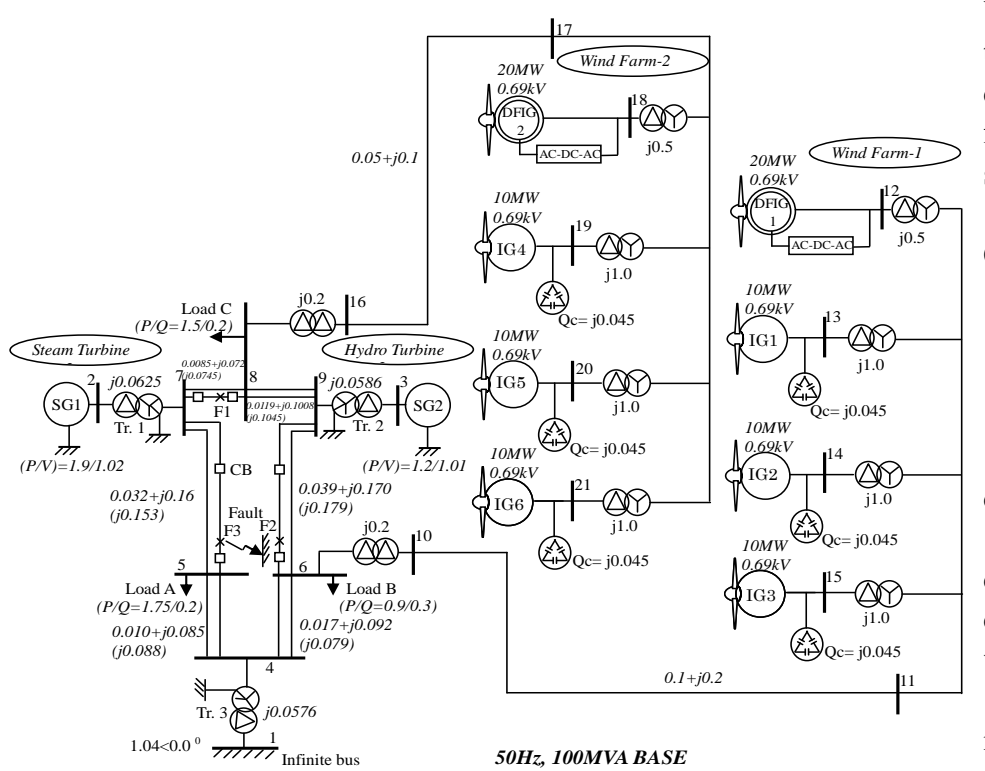

Fig. 1 Model system

\section{Overview of the Effect of Grid Fault on DFIG}

The use of the partial-scale frequency converter in the generator's rotor makes DFIG attractive as a wind generator from an economical point of view. On the other hand, however, this converter arrangement requires advanced protection system, as it is very sensitive to disturbances on the grid $[19,20]$. If there is no protection system, the DFIG can suffer from large transient currents in the stator during a grid fault since its stator circuit is directly connected to the grid. Because of the magnetic coupling between the stator and the rotor, large currents and high voltages appear also in the rotor circuit. Furthermore, the surge following the fault includes a rush of power from the rotor terminals towards the rotor side converter. Therefore there can be a possibility that the desired rotor voltage cannot be maintained and thus the rotor currents cannot be controlled. This means that the rotor side converter can reach to its operating limit and as a consequence it may lose the independent control of real and reactive powers during the grid fault. On the other hand, as the grid voltage drops in the fault moment, the grid side converter is not able to transfer the power supplied from the rotor side converter to the grid, and therefore, the excess energy is stored in the DC-link capacitor, resulting in rapid increase of the DC-bus voltage.

It is therefore necessary to protect the frequency converters against over-currents and the DC-link against overvoltage. The protection system needs to monitor several signals such as rotor current and the DC-link voltage. When at least one of the input signals exceeds its respective relay setting, the protection is activated.

A simple protection approach to the problems of the DFIG due to voltage dips under grid fault is to connect a crowbar circuit to the rotor [21-23]. The crowbar short-circuits the rotor when the DC-link voltage $V_{d c}$ exceeds $V_{d c-m a x}$, and then the inverter connected to the rotor is protected. The crowbar protection is an insertion of external resistance to the rotor via the slip rings. The value of the crowbar resistance is dependent on the generator condition.

An alternative to the crowbar is to connect a protective device between the inverter and converter of the DFIG as used in the VC-VSC DFIG control $[15,24]$. A comparative study between the two protection schemes has been reported in [25], with the conclusion that the latter protection scheme is superior to the former protection scheme due to less components involved and simple switching circuitry.

The DC-link protection scheme can be omitted in the proposed CC-VSC based DFIG strategy as shown in the simulation result.

\section{Current Controlled Voltage Source Converters for DFIG System}

The schematic diagram of DFIG including the proposed current controlled voltage source converter is shown in Fig. 2.

The command signals for the rotor side and the grid side controllers are also shown in Fig 2. An induction generator (IG) is connected at the point of common coupling. The mathematical validation of the converters control is described below [26].

The stator field orientation control is based on the stator d-q model, where the reference frame rotates synchronously with respect to the stator flux, with the d-axis of the reference frame instantaneously overlapping the axis of the stator winding flux. Thus, $\omega=\omega_{e}$ and $\lambda_{q s}=0$. Hence in this reference frame, the machine dynamic equations can be written as [27, 28]: 


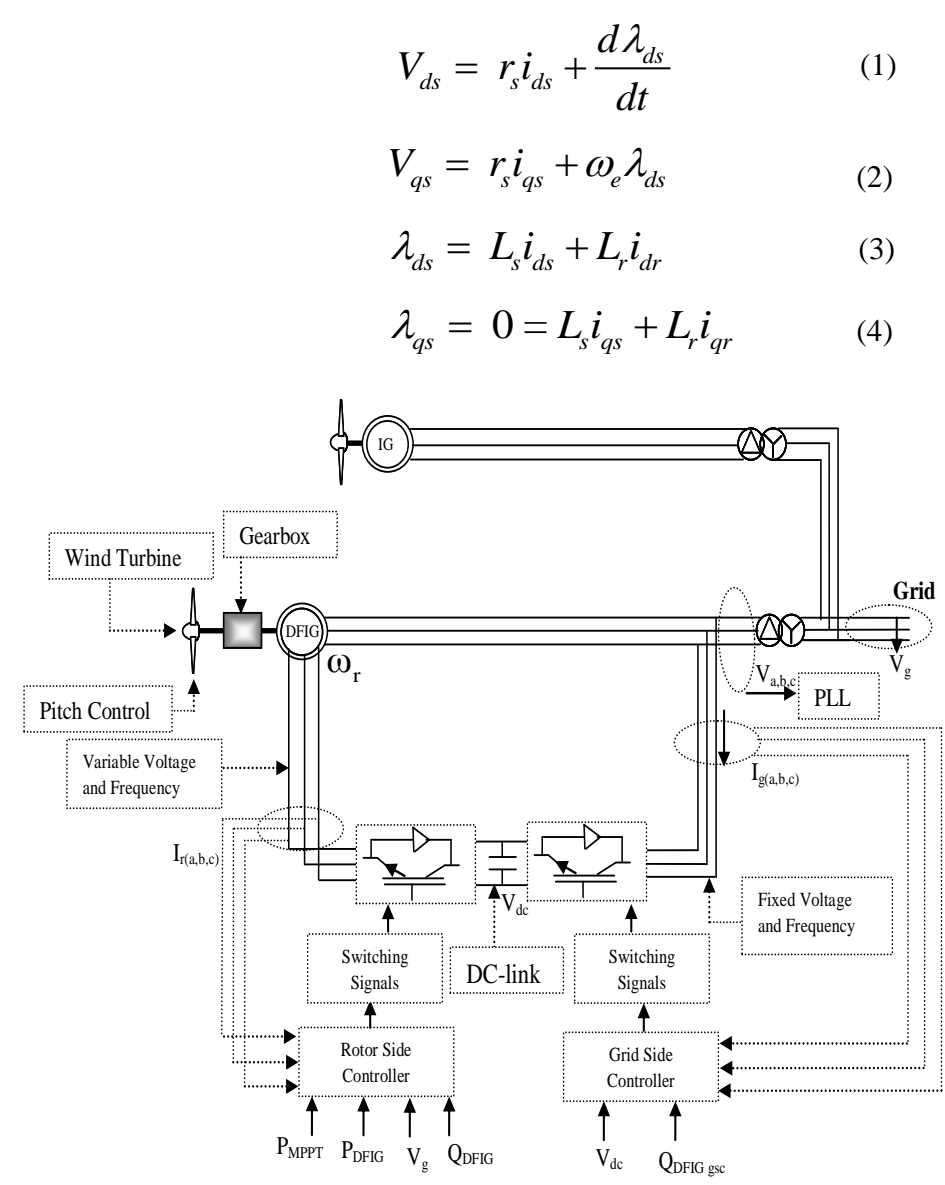

Where, $V_{d s}, V_{q s}$, are the d- and q- axis stator voltage, $\lambda_{d s}, \lambda_{q s}$, are the d- and q- axis stator winding flux, $i_{d s}, i_{q s}$, are d- and qstator current, $i_{q r}$ and $i_{d r}$ are d- and q- axis rotor currents (A) respectively, $L_{s}$ and $L_{r}$ are the stator leakage and rotor self inductances $(\mathrm{H}), \omega_{e}$ is the electrical angular velocity $(\mathrm{rad} / \mathrm{s})$, and $V_{s}$ is the magnitude of the stator phase voltage (V).

Since the d-axis of the reference frame is the instant axis of the stator winding flux, the phase angle of the stator voltage is generally not a constant in the reference frame, although its frequency and magnitude are constants constrained by the power system. The electromagnetic torque and stator active power can be derived as

$$
\begin{gathered}
T_{e}=\frac{3}{2} \frac{p}{2} \lambda_{d s} i_{q r} \\
P_{s}=\frac{3}{2} \frac{p}{2} \omega_{e} \lambda_{d s} i_{q r}
\end{gathered}
$$

Also in the DFIG, the level of the stator flux remains approximately unchanged, restricted by the constant magnitude and frequency of the stator voltage. Therefore, as can be seen from (5), the torque control can be achieved by controlling the rotor current component orthogonal to the stator winding flux. Then from (6), stator active power is subsequently controlled.

From (1) and (2), with the stator flux remaining unchanged, the reactive power can be derived as

$$
Q_{s}=\frac{3}{2} \frac{p}{2} \omega_{e} \lambda_{d s} i_{d r}
$$

Where $p$ is the number of poles in equations (5) to (7).

From (3), $i_{d s}$ is controllable by $i_{d r}$, with $\lambda_{d s}$ unchanged. Therefore, the d-axis component of the rotor current, $i_{d r}$, can be controlled to regulate the stator reactive power.

Grid side converter keeps the DC-link voltage of capacitor constant regardless of the magnitude and direction of rotor power. Neglecting power losses in the converter, capacitor current can be described as follows:

$$
i_{d c}=C \frac{d V_{d c}}{d t}=\frac{3}{4} m i_{\mathrm{gcd}}-i_{d c r}
$$

Where $i_{g c d}$ stands for the $d$-axis current flowing between the grid and grid side converter $(A), i_{d c r}$ is the rotor side DC current $(A), \mathrm{C}$ is the DC-link capacitance $(F)$ and $m$ is the pulse width modulation index of the grid side converter.

The reactive power flowing into the grid from the grid side converter can be expressed as:

$$
Q_{g}=\frac{3}{2} V_{g} i_{g c q}
$$

Where $V_{g}$ is the magnitude of the grid phase voltage $(V)$ and $i_{g c q}$ is $q$-axis current of grid side converter $(A)$. Therefore, it is seen from (8) and (9), DC-link voltage and $Q_{g}$ can be controlled respectively by adjusting $i_{g c d}$ and $i_{g c q}$.

\subsection{Rotor Side Converter Control}

In the rotor side converter (RSC) control shown in Fig. 3, the maximum power point tracking $\mathrm{PMPPT}$ of the wind turbine is compared to the grid power of the DFIG P PFIG to determine the reference signal for active power control. A comparator is used to determine the reference signal of the active and reactive power control during normal and fault conditions of the DFIG based on the grid voltage. During normal operation, when the grid voltage is above $0.9 \mathrm{pu}$, the reference signal of the DFIG real power is the $\mathrm{P}_{\text {MPPT }}$ of the wind turbine. The reference signal for the DFIG reactive power in normal operation is the difference between the grid voltage $(\mathrm{pu})$ and $1.0 \mathrm{pu}$. The error signals are then passed through PI controllers. When the grid voltage is less than $0.9 \mathrm{pu}$ during a grid fault, the comparator regulates the reference signals of the DFIG real and reactive power to zero. In this case, the wind turbine power is reduced to mitigate the overvoltage that is normally experienced in the DC-link in the CC-VSC control strategy. The two reference signals from the controller are then converted from dq to abc using the rotor angle calculated from the phase lock loop (PLL). The reference rotor currents $* \mathrm{I}_{\mathrm{rabc}}$ are then compared to the measured rotor currents $\mathrm{I}_{\mathrm{r}(\mathrm{abc}) \text {. The resultant signal }}$ is then compared with a carrier signal to generate the switching signals for IGBTs in the RSC. It should be noted that the second PI controller is not necessary in the CC-VSC in a different way to the VC-VSC. Also, the dq to abc transformation is only once instead of twice in the VC-VSC. Thus the intricacies of the controller design are reduced. 


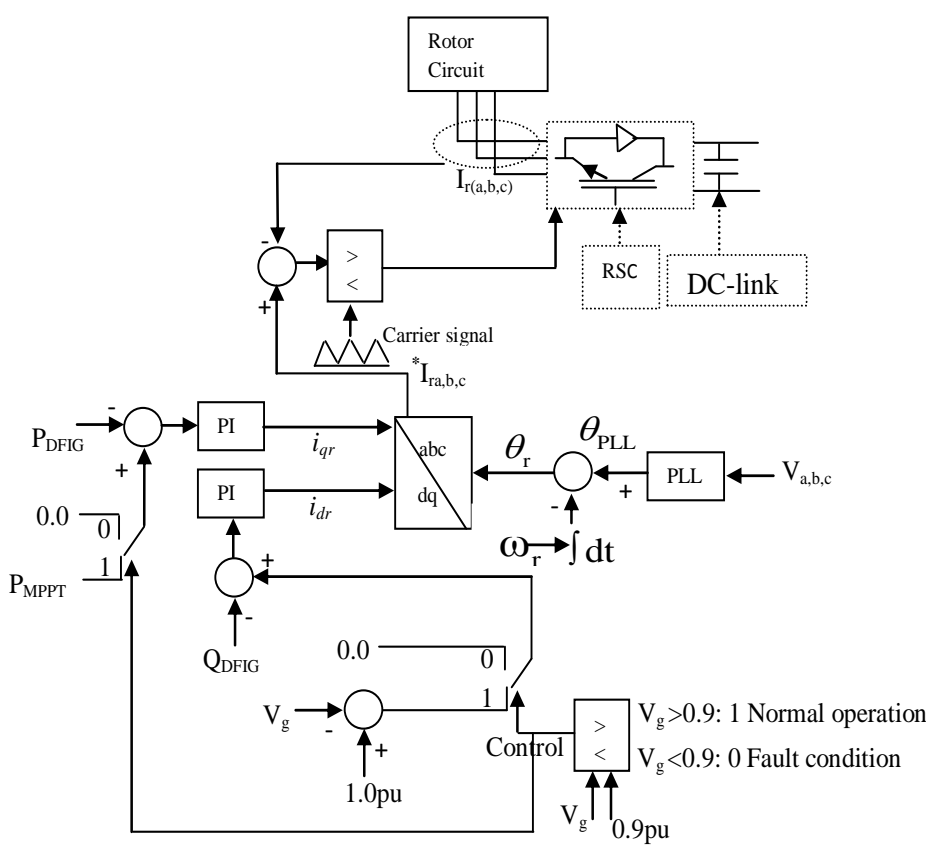

Fig. 3 Block diagram of rotor side converter

\subsection{Grid Side Converter Control}

For the grid side converter (GSC) in Fig. 4, the reference signals for the DC-link voltage and the reactive power of the grid side converter are passed through two PI controllers. The reference signals are then transformed from dq to abc using the stator angle theta. The generated reference signals $* I_{\mathrm{gabc}}$ are then compared to the measured stator currents $I_{g}(a b c)$. The effective signals are then passed through a second PI, before comparing with a carrier signal to generate the reference switching signals for the IGBTs in the GSC.

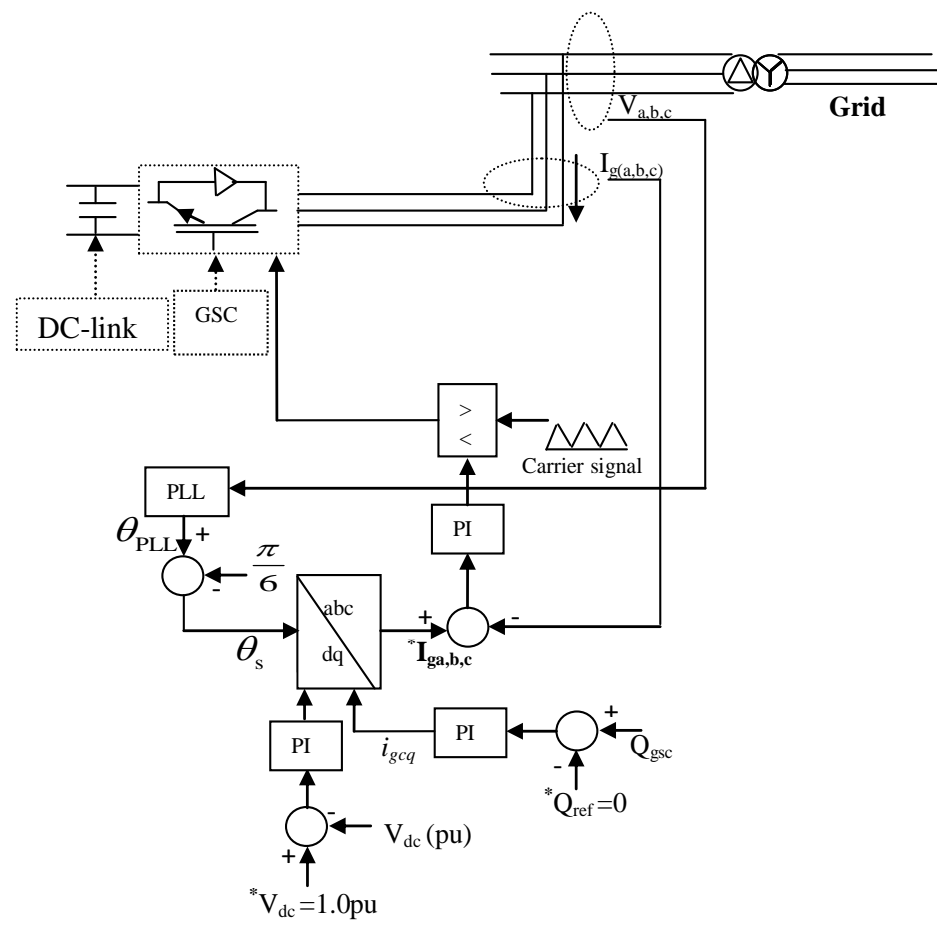

Fig. 4 Block diagram of grid side converter

\section{Grid Codes}

The most worrying problem for wind farms is a voltage dip in the grid during a grid fault [29]. The magnitude of the voltage can be controlled by the reactive power exchange. Fig. 5 displays the typical requirement for fault-ride through grid code. The wind farm must remain connected to the grid if the voltage drop is within the defined r.m.s. value and its duration is also within the defined period as shown in the curve [30].

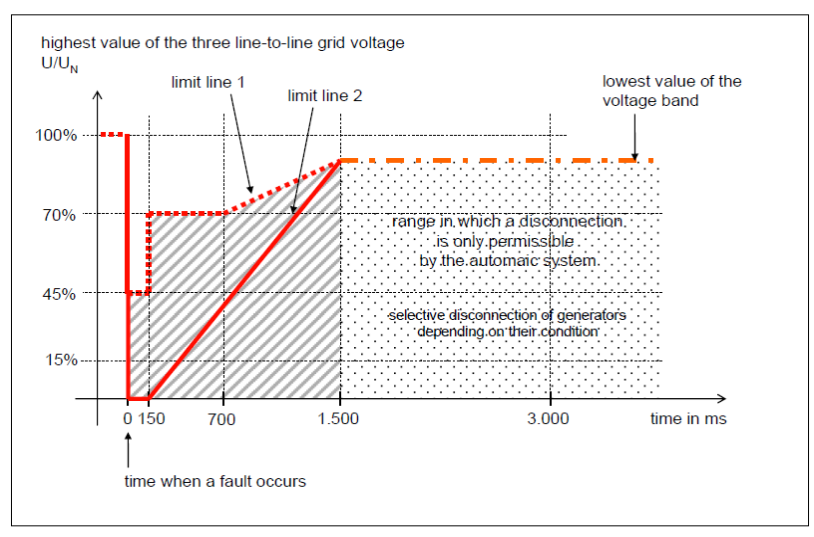

Fig.5 Fault ride through requirement for wind farm

\section{Simulation Results}

To show the effectiveness of the proposed DFIG-based control scheme to stabilize wind farm, three cases were analyzed on simulation analyses. In the first case, the DFIGs were replaced by IGs in the wind farm, which will be referred to "no control". In the second case, the VC-VSC based scheme is considered to control the DFIG. In the third case, the proposed CC-VSC based control scheme is used to control DFIG to show the effectiveness of the proposed control scheme over VC-VSC based scheme. The model system explained in [15], where VC-VSC scheme was reported, is used for the two cases. It should be noted that DC-link protection scheme used in VC-VSC based DFIG [15] is not considered in the CC-VSC based scheme.

All wind generators are assumed to be operated almost at their rated wind speed as shown in Figs. 6 and 7, respectively, for wind farms 1 and 2, where the real wind speed data obtained in Hokkaido Island, Japan, is used. The three-line-to-ground fault (3LG) occurs at $0.1 \mathrm{sec}$ at fault point F2 in the model system. The circuit breakers $(\mathrm{CB})$ on the faulted lines are opened at $0.2 \mathrm{sec}$, and finally, at $1.0 \mathrm{sec}$, the circuit breakers are re-closed. Responses of the network variables and some of the wind generators are shown in Figs.8-21.

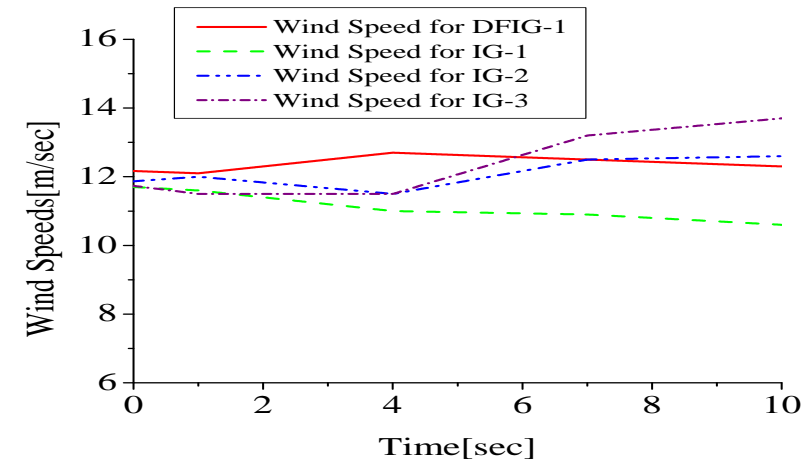

Fig. 6 Wind speeds in wind farm-1 


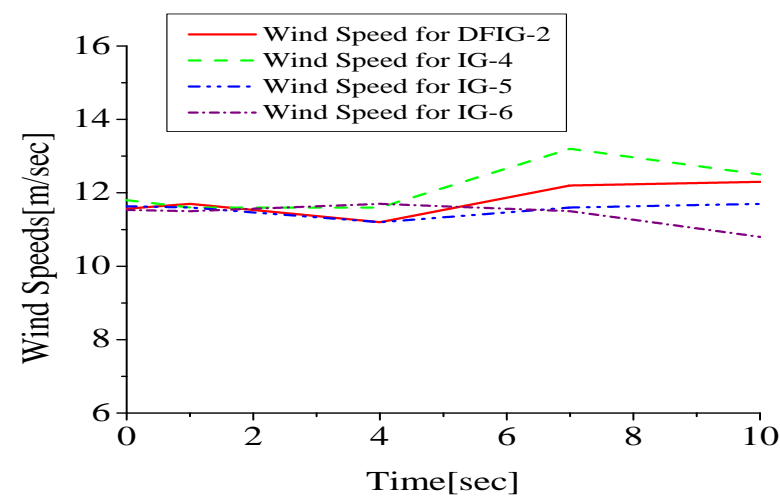

Fig. 7 Wind speeds in wind farm-2

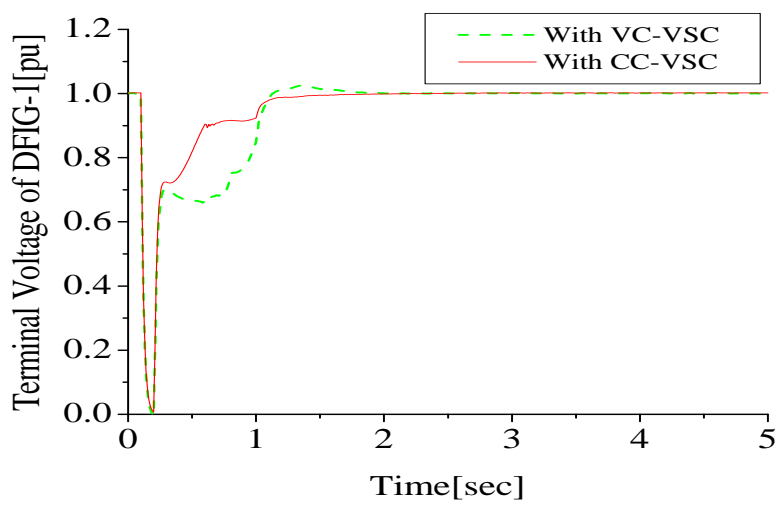

Fig. 8 Terminal voltage of DFIG-1 (3LG)

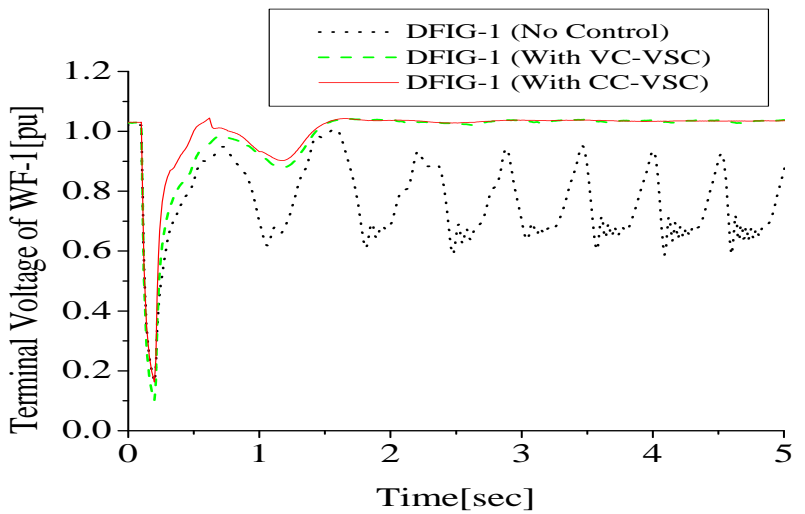

Fig. 9 Terminal voltage (Bus 11) of wind farm-1 (3LG)

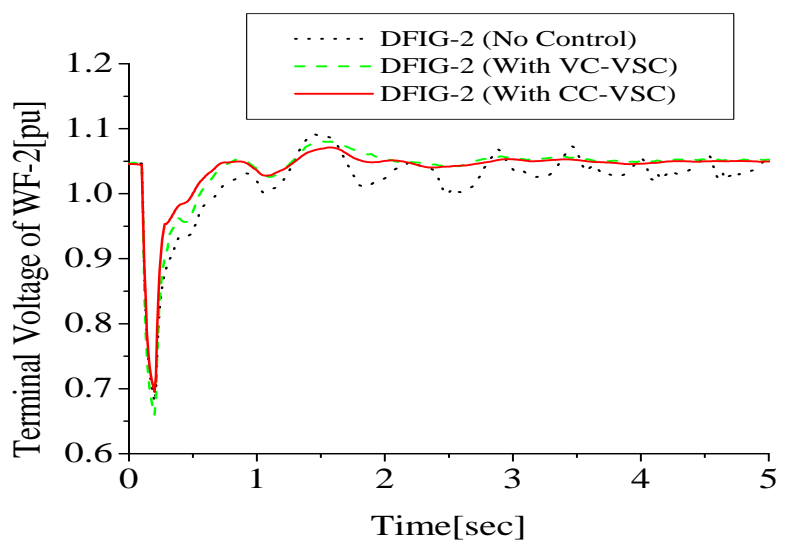

Fig. 10 Terminal voltage (Bus 17) of wind farm-2 (3LG)

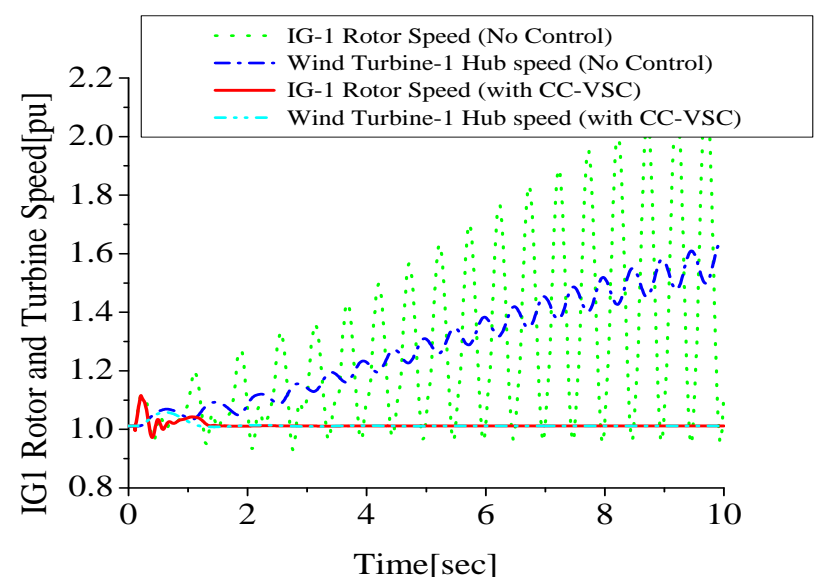

Fig. 11 IG-1 rotor and turbine hub speeds (3LG)

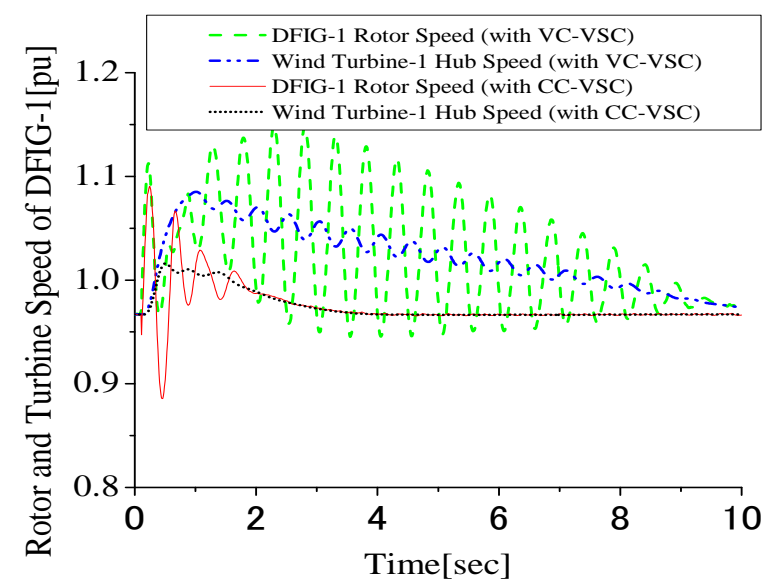

Fig. 12 DFIG-1 rotor and turbine hub speeds (3LG)

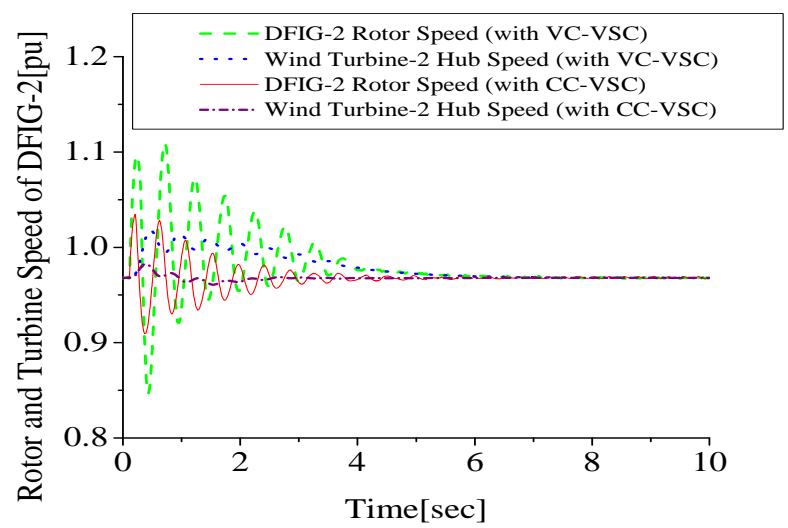

Fig. 13 DFIG-2 rotor and turbine hub speeds (3LG)

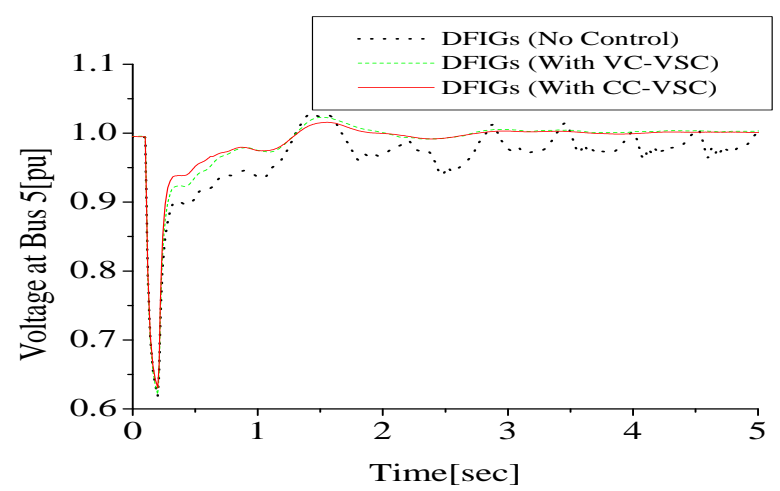

Fig. 14 Voltage at Bus 5 (3LG) 


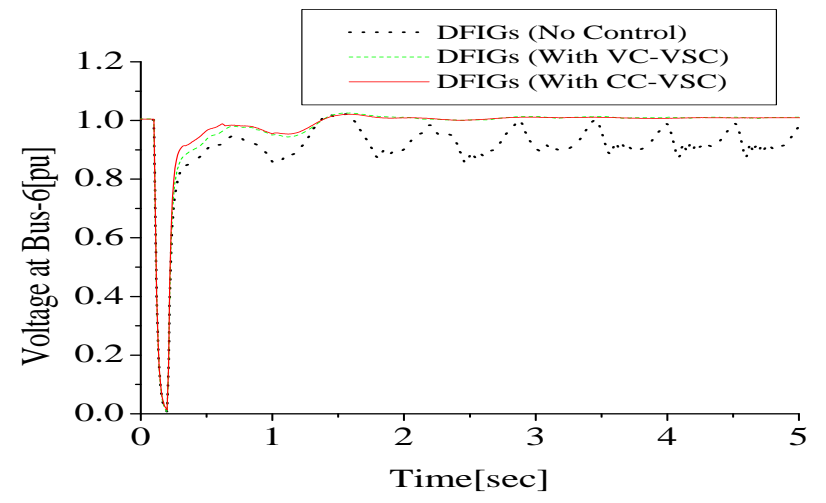

Fig. 15 Voltage at Bus 6 (3LG)

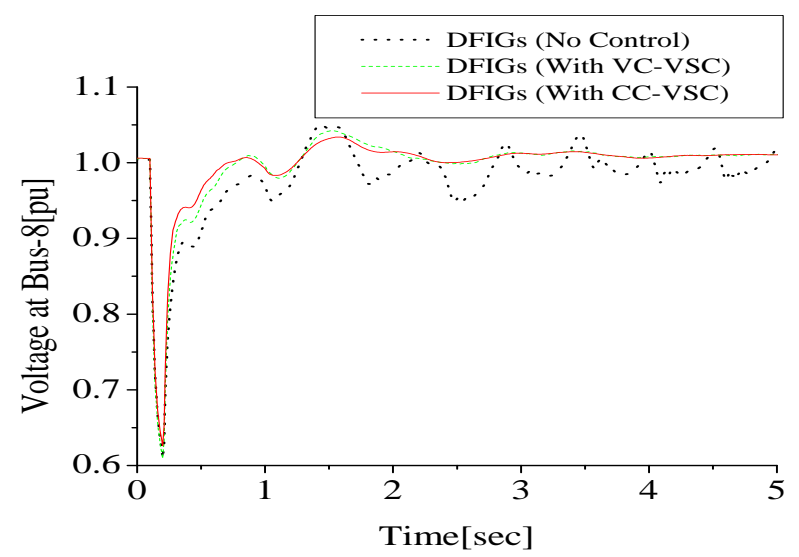

Fig. 16 Voltage at Bus 8 (3LG)

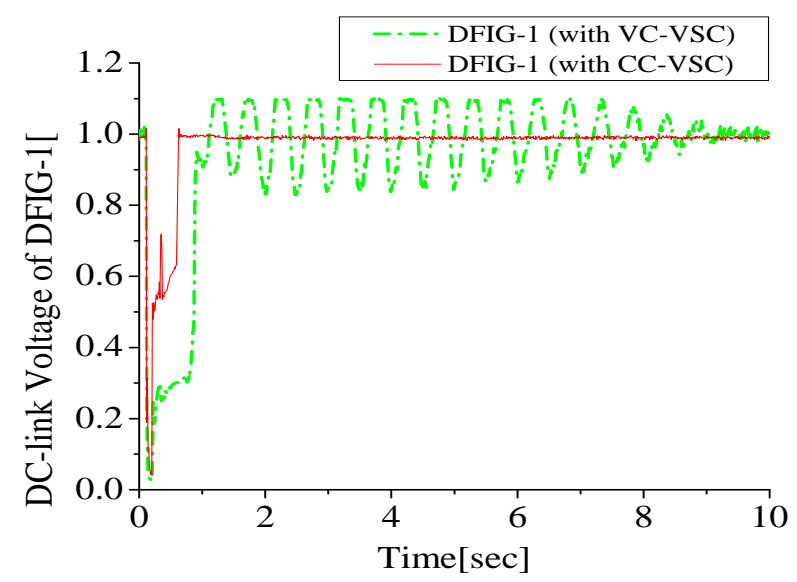

Fig. 17 DC- link voltage of DFIG-1 (3LG)

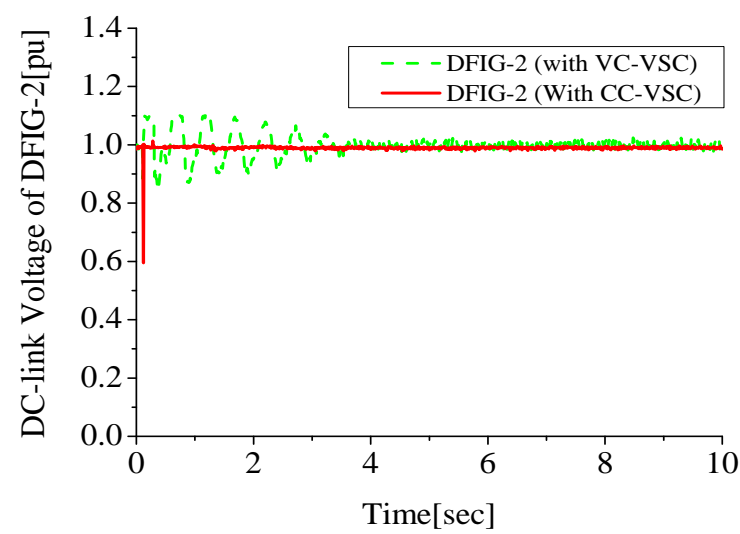

Fig. 18 DC- link voltage of DFIG-2 (3LG)

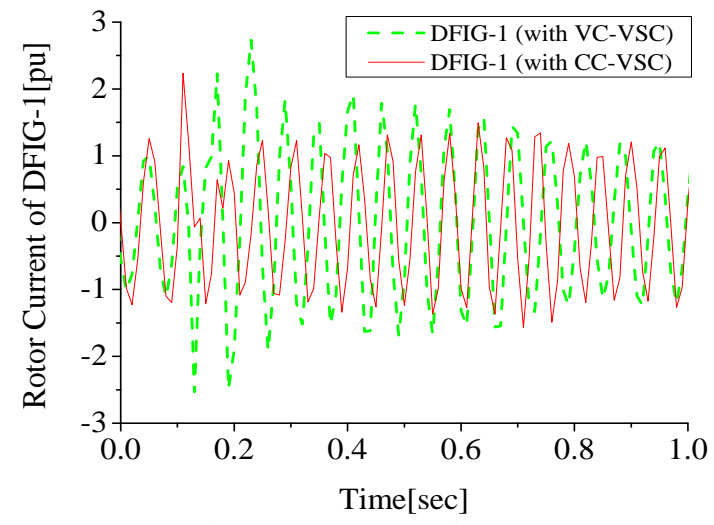

Fig. 19 Rotor current of DFIG-1 (3LG)

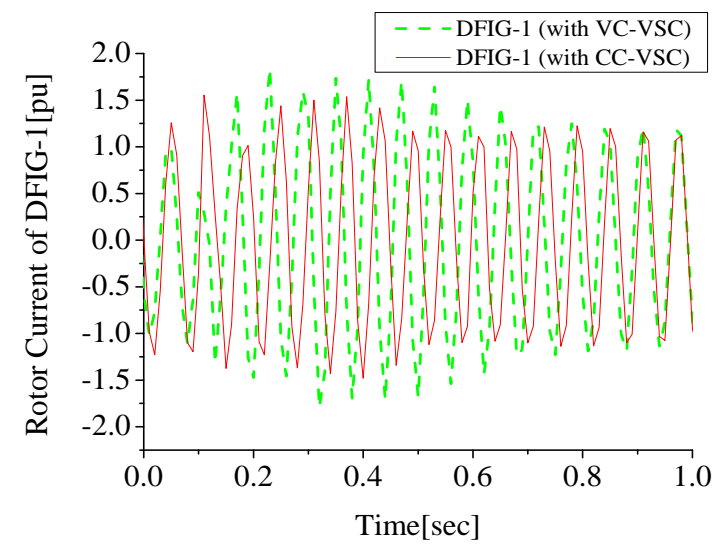

Fig. 20 Rotor current of DFIG-1 (2LG)

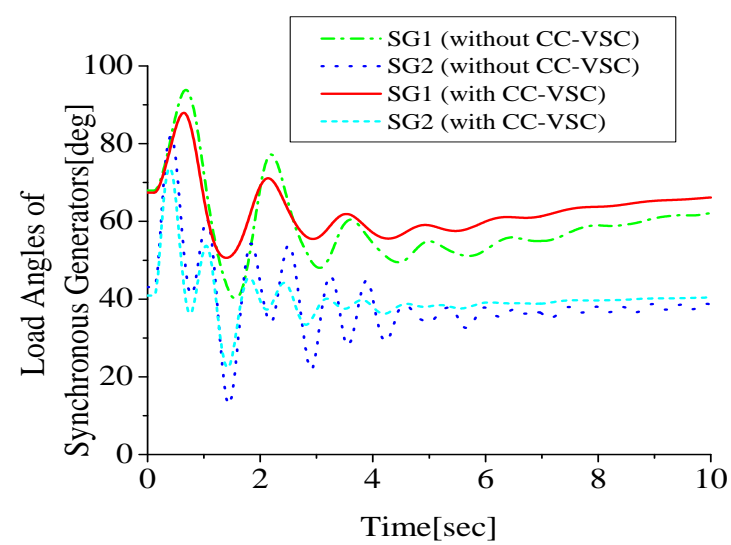

Fig. 21 Load angle of synchronous generators (3LG)

According to the grid codes in Fig. 5, a three-phase short circuit or fault-related symmetrical voltage dips must not lead to instability above the limit line 1 or to disconnection of the generating plant from the grid. Fig. 8 shows the terminal voltage of DFIG-1 in wind farm1. It can be observed that the terminal voltage can be recovered faster in the case of the CC-VSC based control strategy than in the case of the VC-VSC based control strategy. The terminal voltage responses of wind farm 1 and 2 with VC-VSC or CC-VSC based DFIG control strategy considered and without considering DFIG control are shown in Figs. 9 and 10, respectively. When the DFIG control is not considered, the voltage does not recover at the wind farm and also wind generator terminals during the grid fault. Then, the electromagnetic torques of the IGs drop also as the electromagnetic torque is proportional 
to the square of the terminal voltage. The mechanical torques of the wind turbines do not change rapidly during the short time interval. As a result, the turbine hubs and generator rotors accelerate due to the large difference between the mechanical and electromagnetic torques, and then, the wind generators become unstable as shown in Fig. 11. But if the DFIG control is applied, the necessary reactive power is supplied, and then, the terminal voltages of the wind farm and the electromagnetic torques of the IGs can be restored quickly making the wind generators stable. The DFIG control using voltage/current source based VSC was used to achieve the grid requirement as stipulated in Fig. 5, where the voltage control must take place within $1.5 \mathrm{sec}$ after fault recognition as shown in Fig. 5. However, the responses using the CC-VSC based DFIG control is better than those of the VC-VSC based DFIG control. Figs. 12 and 13 show the responses of the DFIGs rotor and wind turbine hub speeds. The rotor and the wind turbine hub speeds can recover to their steady state faster and with less oscillation in the case of the CC-VSC based DFIG control. Figs.14-16 show the responses of the voltages at bus 5, 6 and 8 from which fast voltage recovery at these busses in the case of CC-VSC is also evident.

The DC-link voltages of the DFIGs are shown in Figs. 17 and 18 in the cases of VC-VSC and the proposed CC-VSC, respectively. It is seen that the overvoltage in the DC-link voltage during grid fault, can be reduced significantly using VC-VSC with the help of DC-link protective device. It is also found that DC-link protection scheme can even be completely omitted when the proposed CC-VSC based control is adopted. The impact of the grid fault on the DC-link voltage in DFIG-1 is more than DFIG-2, because the fault occurs closer to wind farm-1. Also, to show that the proposed CC-VSC can effectively control overcurrent in the rotor side converter of the DFIG, two-line-to-ground fault (2LG) at the same location was also analyzed in addition to $3 \mathrm{LG}$ fault as shown in Figs. 19 and 20 respectively. The rotor current of DFIG-1 could be effectively controlled within twice its nominal value for both fault conditions in the case of CC-VSC. Hence, the normal operation of the converter can be kept continuing during the grid fault using the proposed CC-VSC, but in the case of VC-VSC the rotor current goes up to almost three times its nominal value. Fig. 21 shows the responses of the load angles of SG-1 and SG-2. When the CC-VSC based DFIGs are connected, better responses of the load angles can be obtained.

\section{Transient Stability Evaluation of the System}

The transient stability index, Wc, [31] defined as follows is used in evaluating the transient stability of the system:

$$
W(\mathrm{sec})=\int_{0}^{T} a b s\left(\frac{d}{d t} W_{\text {tota }}\right) d t / \text { system base power }
$$

Where $\mathrm{T}$ is the simulation time (10.0sec here), and Wtotal is the total kinetic energy calculated by using the rotor speed of each synchronous generator as follows:

$$
W_{\text {total }}=\sum_{i=1}^{N} W_{i}(J)
$$

$$
W_{i}=\frac{1}{2} J_{i} \omega_{m i}^{2}(J)
$$

Where $\mathrm{N}$ is the number of synchronous generators, and $J_{i}$ and $\omega_{i}$ denote inertia moment and rotor speed of each synchronous generator. The smaller the value of $\mathrm{Wc}$, the better the system transient stability. The transient stability index against 1LG (one-line-to-ground fault), 2LS (line-to-line fault), 2LG, and 3LG faults with and without considering the CC-VSC DFIG control are shown in Table 1, for the different fault points in the model system. From these results it can be understood that the proposed CC-VSC DFIG control can improve the transient stability of the entire power system.

Table 1: Transient Stability Index [Wc(s)] of the System

\begin{tabular}{|c|c|c|c|c|c|c|}
\hline & \multicolumn{3}{|c|}{ Without DFIG } & \multicolumn{3}{c|}{$\begin{array}{c}\text { With CC-VSC Controlled } \\
\text { DFIG }\end{array}$} \\
\hline \multirow{2}{*}{ Fault } & \multicolumn{3}{|c|}{ Fault Location } & \multicolumn{3}{c|}{ Fault Location } \\
\cline { 2 - 7 } & F1 & F2 & F3 & F1 & F2 & F3 \\
\hline 3LG & 4.86 & 3.98 & 4.62 & 3.39 & 2.50 & 3.11 \\
\hline 2LG & 3.42 & 2.32 & 3.34 & 2.88 & 1.64 & 2.49 \\
\hline 2LS & 2.98 & 2.31 & 2.81 & 2.41 & 1.65 & 2.07 \\
\hline 1LG & 2.23 & 1.66 & 2.22 & 1.78 & 1.19 & 1.56 \\
\hline
\end{tabular}

\section{Dynamic Analysis of the Proposed Scheme}

The purpose of this analysis is to observe the performance of the CC-VSC based DFIG in real wind situation. A simple model system where a DFIG and IG are connected to an infinite bus as shown in Fig. 22 was considered in this analysis. Simulation analyses were run for $600 \mathrm{sec}$, using real wind speed data obtained in Hokkaido Island, Japan. Figure 23 shows the natural wind speed, while Fig. 24 shows the maximum power point tracking (MPPT) and the grid power of the DFIG. It could be seen that the grid power of the DFIG follows the MPPT reference power of the wind turbine. In Fig. 25, the rotor speed of the DFIG follows the wind turbine optimum speed. The grid voltage response with and without considering the CC-VSC based DFIG is shown in Fig. 26. It can be observed that the proposed CC-VSC based DFIG can also maintain wind farm terminal voltage constant in dynamic condition. This analysis ensures that the proposed control scheme works well not only for fault condition, but also in dynamic condition.

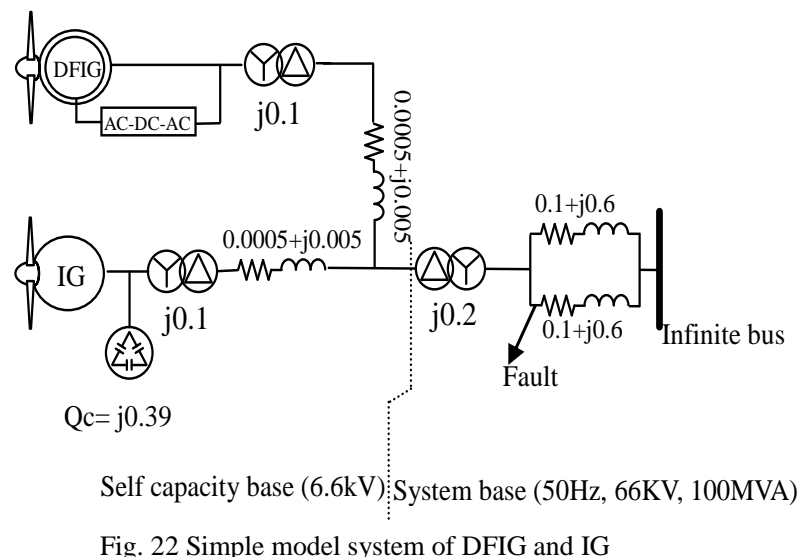

Fig. 22 Simple model system of DFIG and IG 


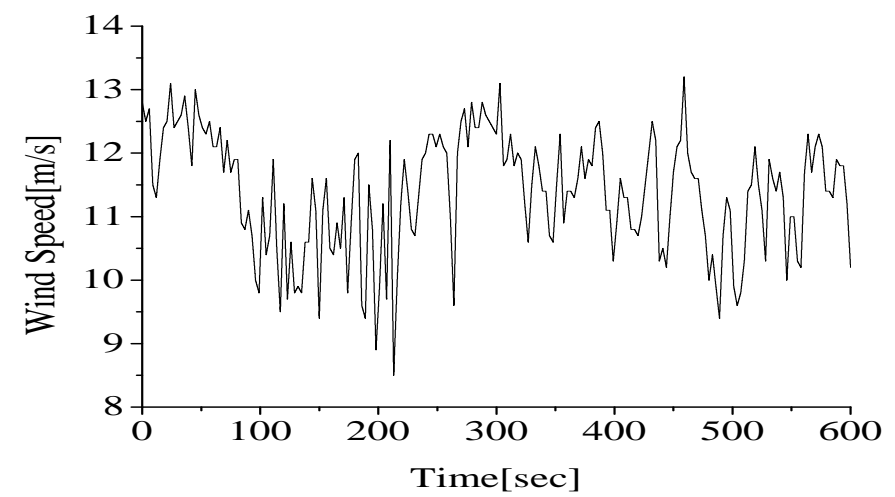

Fig. 23 Wind speed

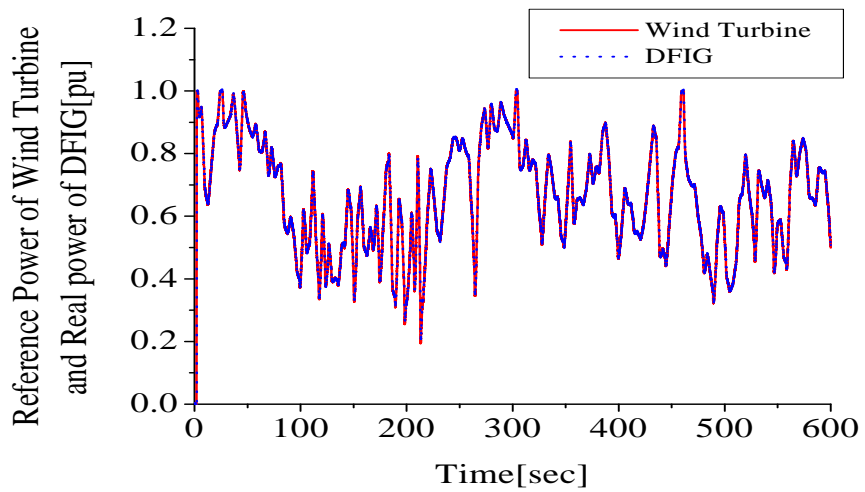

Fig. 24 Wind turbine reference power and DFIG real power

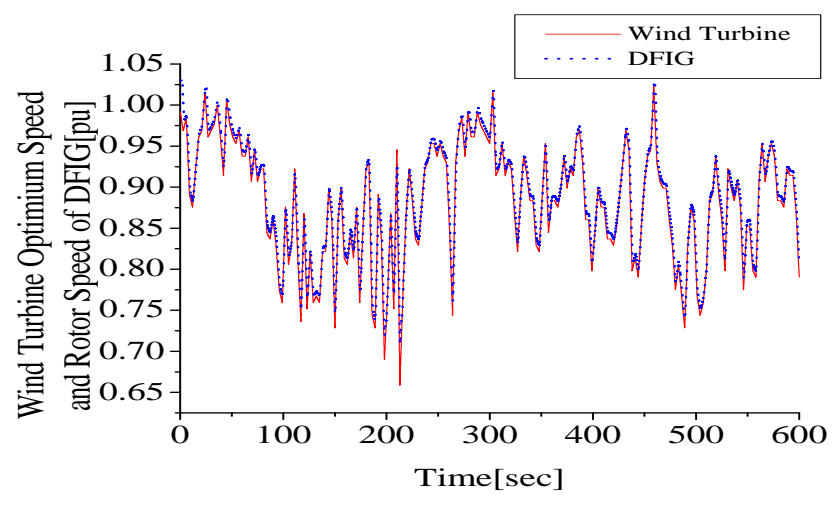

Fig. 25 Wind turbine optimum speed and DFIG rotor speed

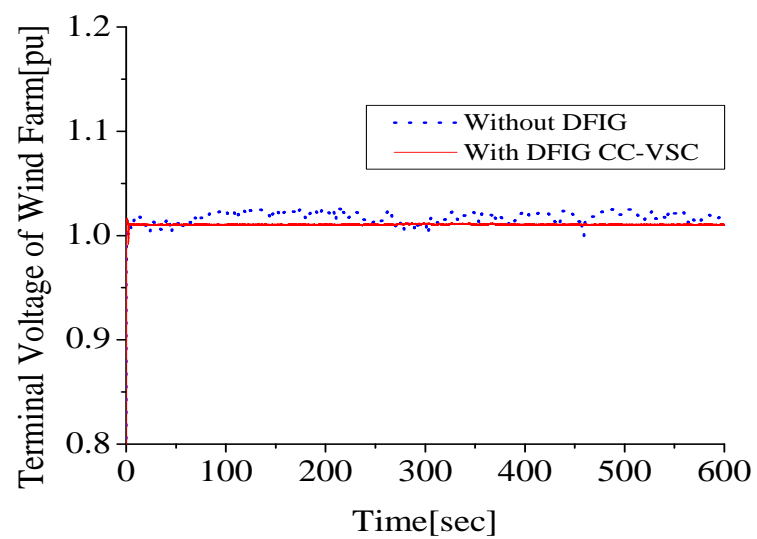

Fig. 26 Terminal voltage of wind farm

\section{Conclusion}

A new control method for DFIG wind generators using current controlled voltage source converters to stabilize wind farms composed of both fixed speed and variable speed wind turbine generators has been proposed. The proposed CC-VSC based DFIG control strategy offers the advantages of reduced PI controllers at the RSC, omission of DC-link protective device and less intricacy of controller designing. The effectiveness of the proposed control method has been verified by simulation analyses for several symmetrical and unsymmetrical faults in the multi-machine power system. It has been found that, when the DFIG controlled by the proposed method is incorporated in the wind farm, IGs as well as DFIGs in the wind farms become stable. It has also been found that CC-VSC based DFIG gives better performance compared to the VC-VSC based DFIG scheme to improve dynamic and transient performances of the overall system. Therefore, it can be concluded that the proposed control method for variable speed wind turbine driving DFIG can be an effective means to enhance the transient stability of the grid connected wind farms.

\section{Acknowledgement}

The authors would like to acknowledge Japan Gas Corporation (JGC) and The Petroleum Institute, Abu Dhabi, UAE, for their support in this work.

(Manuscript received Aug.15, 2011, revised Sept. 23, 2011, Accepted Nov. 17, 2011.)

\section{References}

(1) D. Xiang, L. Ran, P. Tavner, and S. Yang: "Control of doubly fed induction generator in a wind turbine during grid fault ride-through," IEEE Trans. Energy Conversion, vol. 21, no. 3, pp. 652-662 (2006).

(2) M. P. Papadopoulos, S. A. Papathanassiou, N. G. Boulaxis, and S. T Tentzerakis: "Voltage quality change by grid-connected wind turbines," European Wind Energy Conference, Nice, France, pp.783-785 (1999).

(3) A. H. Kasem, E. F. El-Saadany, H. H. El-Tamaly, and M. A. A. Wahab: “An improved fault ride-through strategy for doubly fed induction generator-based wind turbines," IET Renewable Power Generation, vol.2 , no. 4, pp. 201-214 (2008).

(4) J. A. Suul, M. Molinas and T. Undeland: "STATCOM-based indirect torque control of induction machines during voltage recovery after grid faults," IEEE Trans. on Power Electronics, vol. 25, no. 5, pp. 1240-1250 (2010).

(5) J.Yu, X. Duan, Y. Tang and P. Yuan: "Control scheme studies of voltage source type superconducting magnetic energy storage (SMES) under asymmetrical voltage," IEEE Trans. on Applied Superconductivity, vol.12, no. 1 , pp. $750-753$ (2002).

(6) S.M. Muyeen, R. Takahashi, M.H. Ali, T. Murata, and J. Tamura: "Transient stability augmentation of power systems including wind farms using ECS," IEEE Tans. on Power Systems, vol. 23, no. 3, pp. 1179-1187 (2008).

(7) A. A. El-Sattar, et-al.: "Dynamic response of doubly fed induction generator variable speed wind turbine under fault," Electric Power System Research, pp. 1240-1246 (2008).

(8) S. Santos and H. T. Le: "Fundamental time-domain wind turbine models for wind power studies," Renewable Energy, vol. 32, pp. 2436-2452 (2007).

(9) B. H. Chowdhury and S. Chellapilia: "Doubly-fed induction generator control for variable speed wind power generation," Electric Power System Research, vol. 76, pp. 786-800 (2006).

(10) H. Karim-Davijani, A. Sheikjoleslami, H. Livani and M. Karimi-Davijani: "Fuzzy logic control of doubly fed induction generator wind turbine," World Applied Science Journal, vol. 6, no. 4, pp. 499-508 (2009).

(11) T. Sun, Z. Chen and F. Blaabjerg: "Transient stability of DFIG wind turbines at an external short circuit fault," Wind Energy Journal, vol. 8, pp. 345-360 (2005).

(12) I. Erlich, H. Wrede and C. Feltes: "Dynamic behavior of DFIG-based wind turbine during grid faults," IEEJ Trans. Industrial Application, vol. 128, no. 4, pp. 396-401 (2008).

(13) S. M. Muyeen, M. H. Ali, R. Takahashi, T. Murata, J. Tamura, Y. Tomaki, A. 
Sakahara, and E. Sasano: "Comparative study on transient stability analysis of wind turbine generator system using different drive train," IET Renewable Power Generation, 2, vol. 1, no. 2, pp.131-141 (2007).

(14) PSCAD/EMTDC Manual": Manitoba HVDC research center (1994).

(15) K. E. Okedu, S. M. Muyeen, R. Takahashi, and J. Tamura: "Stabilization of wind farms by DFIG-based variable speed wind generators," International Conference of Electrical Machines and Systems (ICEMS), Seoul, South Korea (2010), available online IEEE Explorer.

(16) Working Group on Prime Mover and Energy Supply Models for System Dynamic Performance Studies: "Hydraulic turbine and turbine control models for fossil fueled steam units on power system studies," IEEE Trans. Power System, vol. 6, no. 2, pp. 753-761 (1991).

(17) Working Group on Prime Mover and Energy Supply Models for System Dynamic Performance Studies: "Hydraulic turbines and turbine control models for system dynamic studies," IEEE Trans. Power System, vol. 7, no. 1, pp. 167-179 (1992).

(18) "IEEE Recommended Practice for Excitation System Models for Power System Stabillity Studies" :IEEE STD, (1992); 421.5.

(19) A. D. Hassan and G. Michalke: "Fault ride-through capability of DFIG wind turbines," Renewable Energy, vol. 32, pp. 1594-1610 (2007).

(20) A. Petersson: "Analysis, modeling and control of doubly-fed induction generators for wind turbines," $\mathrm{PhD}$ Thesis, Division of Electric Power Engineering, Department of Energy and Environment, Chalmers University of Technology, Sweden (2005).

(21) V. Akhmatov: "Analysis of dynamic behavior of electric power systems with large amount of wind power," PhD Thesis, Orsted, DTU (2003).

(22) J. Niiranen: "Voltage ride through of a doubly-fed generator equipped with an active crowbar," Nordic Wind Power Conference (2004).

(23) J. Niiranen: "Simulation of doubly fed induction generator wind turbine with an active crowbar," EPE-PEMC, Riga, Latvia (2004).

(24) R. Takahashi, J. Tamura, M. Futami, M. Kimura and K. Idle: "A new control method for wind energy conversion system using double fed synchronous generators," IEEJ Trans. Power and Energy, vol. 126, no. 2, pp. 225-235 (2006) (in Japanese)

(25) K. E. Okedu, S. M. Muyeen, R. Takahashi and J. Tamura: "Comparative study between two protection schemes for DFIG-based wind generator," International Conference of Electrical Machines and Systems (ICEMS), Seoul, South Korea (2010), available online IEEE Explorer.

(26) K. E. Okedu, S. M. Muyeen, R. Takahashi and J. Tamura: "Comparative study on current and voltage controlled voltage source converter based variable speed wind generator," International Conference on Electric Power and Energy Conversion System (EPECS`11), Sharjah, UAE (Nov. 2011).

(27) M. Yamamoto and O. Motoyoshi: "Active and reactive power control for doubly fed wound rotor induction generator," IEEE Trans. Power Electronics, vol. 6, no. 4, pp. 624-629 (1991).

(28) B. K. Bose, Power electronics and AC drives, New Jersey: Prentice-Hall, pp. 46-52 (1986).

(29) S. Heir, Grid Integration of Wind Energy Conversion Systems, ISBN: 0-471-97143 (1998).

(30) E.ON NETZ GmbH: Grid connection regulation for high and extra high voltage (2006).

(31) M. Yagami, S. Shibata, T. Murata and J. Tamura: "An analysis of superconducting fault current limiter for stabilization of synchronous generator in multi-machine system: A two-machine infinite bus system," IEEJ Trans. PE, vol. 123, no. 2, pp. 133-142 (2003).
S. M. Muyeen (Non member) received his B.Sc. Eng. Degree from Rajshahi University of Engineering and Technology (RUET), Bangladesh, formerly known as Rajshahi Institute of Technology, in 2000, and M. Sc. Eng. and Dr. Eng. Degrees from Kitami Institute of Technology, Japan, in 2005 and 2008 respectively, all in Electrical and Electronic Engineering. After completing his $\mathrm{Ph} . \mathrm{D}$. program he worked as a Postdoctoral Research Fellow under the versatile banner of Japan Society for the Promotion of Science (JSPS) from 2008-2010 at the Kitami Institute of Technology, Japan. Presently he is working as Assistant Professor in Electrical Engineering department at the Petroleum Institute, UAE. His research interests are power system stability and control, electrical machine, FACTS, energy storage system (ESS), renewable energy, and HVDC system. Dr. Muyeen is a member of IEEE.

Rion Takahashi (Member) received the B.Sc. Eng. and Dr. Eng. Degrees from Kitami Institute of Technology, Japan, in 1998 and 2006 respectively, all in Electrical and Electronic Engineering. Now he is working as Associate Professor in Department of Electrical and Electronic Engineering, Kitami Institute of Technology. His major research interests include analysis of power system transient, FACTS and wind energy conversion system. He is a member of IEEE.

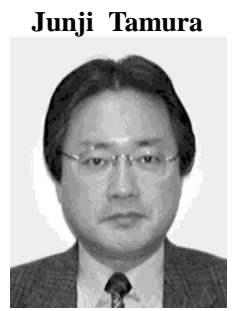

(Member) received his B. Sc. Eng. Degree from Muroran Institute of Technology, Japan, in 1979 and M.Sc. Eng. and Dr. Eng. degrees from Hokkaido University, Japan, in 1981 and 1984 respectively, all in electrical engineering. $\mathrm{He}$ became a lecturer in 1984, an Associate Professor in 1986, and a Professor in 1996 at the Kitami Institute of Technology, Japan. Currently he is a Vice President of the Kitami Institute of Technology. Dr. Tamura is a Senior Member of the IEEE Power Engineering Society.
Kenneth Eloghene Okedu (Non-member) is currently a Ph.D. student

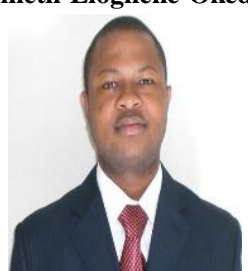
in the department of Electrical and Electronic Engineering, Kitami Institute of Technology, Hokkaido, Japan. He received his B.Sc. and M. Eng. degrees in Electrical and Electronic Engineering from the University of Port Harcourt, Nigeria in 2003 and 2006 respectively. His research interests include the stabilization of wind farm with doubly fed induction wind generator variable speed wind turbine, and power system stability analysis. 